\title{
Delayed stomach to caecum transit time in the diabetic rat. Possible role of hyperglucagonaemia
}

\author{
J Chesta, E S Debnam, S K S Srai, O Epstein
}

\begin{abstract}
Disturbances of gastrointestinal motility are a common feature of diabetes mellitus and are usually ascribed to autonomic neuropathy. In order to assess the role of other factors on changes in motility in diabetes we have studied the stomach to caecum transit time (SCTT) during the progression of streptozotocin induced diabetes in the rat. Rats were used one, two, four, and eight weeks after a single injection of streptozotocin and age matched animals were used as controls. In further experiments non-diabetic rats received a bolus injection of pancreatic glucagon $(50$ or $75 \mu \mathrm{g}$ intraperitoneally) or its diluent. SCTT was estimated using the non-invasive hydrogen excretion method. SCTT was unaffected by the age of the animal (mean (SEM) value: 101 (5) $\mathrm{min}$ ), but was significantly delayed at one week (139 (11) $\mathrm{min}, \mathrm{p}<0.01$ ), two weeks (163 (16) $\mathrm{min}, \mathrm{p}<0.01$ ), four weeks (148 (9) $\mathrm{min}$, $p<0.01$ ), and eight weeks (171 (13) min, $\mathbf{p}<0.01$ ) after streptozotocin. SCTT was also slower during hyperglucagonaemia (control 96 (6) min; glucagon treated $50 \mu \mathrm{g}: 120$ (7) $\mathrm{min}$, $\mathrm{p}<0.05$ and $75 \mu \mathrm{g}: 127(8), \mathrm{p}<0.05)$. Since autonomic neuropathy is not a recognised feature of the initial stages of diabetes hyperglucagonaemia may be responsible, at least in part, for diabetes induced changes in gastrointestinal motility.
\end{abstract}

Abnormalities of gastrointestinal motility are common in diabetes mellitus. ${ }^{1}$ In particular diarrhoea and disturbances of gastric emptying occur in patients with this disease. ${ }^{2-4}$ Although diabetes is associated with degenerative changes in the peripheral nervous system, there is conflicting information on the involvement of diabetic neuropathy in the pathogenesis of gastrointestinal disorders. ${ }^{48}$ Since a knowledge of changes in gut motility during the progression of the disease might be important in understanding diabetic gastroenteropathy we measured stomach to caecum transit time (SCTT) one to eight weeks after the induction of diabetes in the rat. These times were chosen as raised levels of pancreatic glucagon after one week have been reported, ${ }^{9}$ whereas morphological and functional evidence for autonomic neuropathy is also a feature at eight weeks. ${ }^{10-13}$ In further experiments we studied the effect of glucagon administration on SCTT in non-diabetic rats.

\section{Methods}

Dr Owen Epstein, Academ Department of Medicine, Royal Free Hospital School of Medicine, London NW3 2OG.

Accepted for publication 29 August 1989

ANIMAL PREPARATION

Male Sprague-Dawley rats (average body weight
$249 \mathrm{~g}$ ) were made diabetic using streptozotocin $(60 \mathrm{mg} / \mathrm{kg}$, dissolved in $\mathrm{pH} 4.5$ citrate buffer) administered via a dorsal tail vein while aged matched controls were injected with buffer alone. Both groups of animals were allowed chow and water ad libitum. Animals injected with streptożotocin became glycosuric after two days and failed to gain weight over the period of the study. The mean (SEM) plasma glucose concentration was $24 \cdot 1(2 \cdot 2) \mathrm{mM}(\mathrm{n}=10)$ and $36 \cdot 4(2 \cdot 1)$ $\mathrm{mM}(\mathrm{n}=12)$ at one and four weeks respectively.

To assess the effect of hyperglucagonaemia on SCTT, rats $(300-400 \mathrm{~g})$ received $50 \mu \mathrm{g}$ or $75 \mu \mathrm{g}$ (intraperitoneally) of pancreatic glucagon (Novo Industria $\mathrm{A} / \mathrm{S}$, Denmark) dissolved in $1.6 \%$ glycerin with $0 \cdot 2 \%$ phenol. Rats treated with diluent were used as controls. Injections were given immediately before intragastric gavage.

\section{MEASUREMENT OF SCT T}

After an overnight fast rats were housed singly in Perspex chambers (volume 61 ) which allowed free movement. Room air was pumped at $125 \mathrm{ml}$ min through the chamber and effluent air samples (volume $20 \mathrm{ml}$ ) were removed in duplicate at 10 min intervals during one hour before and up to four hours after intragastric gavage of a $5 \mathrm{ml}$ homogenate of baked beans in $10 \%$ lactulose. ${ }^{14}$ The use of an electrically driven fan in the chamber ensured adequate mixing of air before sampling. Air samples were analysed immediately using a hydrogen monitor (GMI Medical Limited, Renfrew, Scotland) and SCTT was defined as the time taken (in min) from gavage to initiate a rapid and sustained rise in hydrogen levels (more than $5 \mathrm{ppm}$ above baseline for two consecutive time points).

EFFECT OF LACTULOSE ON TRANSMURAL POTENTIAL DIFFERENCE (PD)

Using the above criteria some animals failed to show an increase in hydrogen excretion after intragastric gavage and an additional procedure was carried out to obtain information on the possible effect of mucosal lactulase activity. Rats were anaesthetised using pentobarbitone sodium (90 mg/kg ip; Sagatal, May and Baker Ltd) and after laparotomy a $15 \mathrm{~cm}$ length of upper jejunum was selected, washed through with warm $\mathrm{NaCl}(154 \mathrm{mM})$, and cannulated at each end. The cannulas were connected to a fluid circuit through which gassed $\left(95 \% \mathrm{O}_{2}: 5 \% \mathrm{CO}_{2}\right)$ bicarbonate saline (pH 7.4), warmed to $37^{\circ} \mathrm{C}$, was pumped $(2 \mathrm{ml} / \mathrm{min}$ ) using a peristaltic pump. Rectal temperature was maintained at $37^{\circ} \mathrm{C}$ using a heated blanket. The pd across the intestine was 


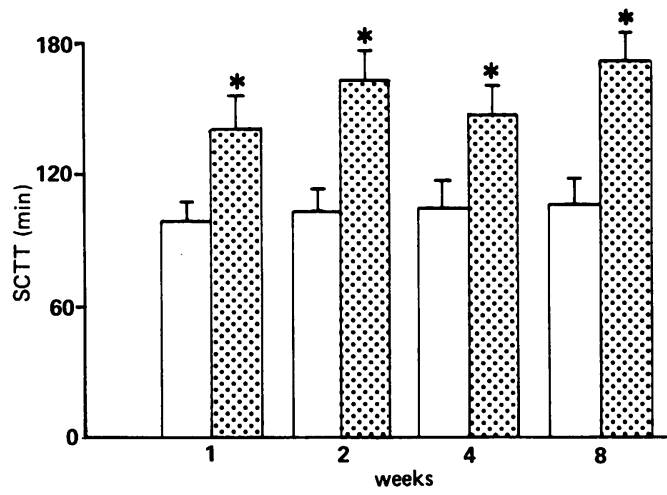

Figure 1: Changes in the stomach to caecum transit time (SCTT) during the progression of streptozotocin induced diabetes in the rat (hatched bars) in comparison with age matched controls (open bars) $\left({ }^{\star} p<0.01\right.$ compared to control values).

inserted into the proximal cannula while another made contact with the peritoneal surface of intestine. ${ }^{15}$ The salt bridges led to calomel cells connected to the input terminals of a high input impedance electrometer (Model 602, Keithley Instruments, Cleveland, Ohio), the output of which was connected to a chart recorder (Model BD 41, Kipp \& Zonen, FT Instruments, Gloucestershire). The change in pd induced by adding lactulose ( $50 \mathrm{mM})$ to the buffer for $15 \mathrm{~min}$ duration was recorded and compared with the osmotically induced pd obtained using mannitol $(50 \mathrm{mM})$. The effect of galactose $(50 \mathrm{mM})$ and sucrose $(50 \mathrm{mM})$ on pd was also studied.

\section{STATISTICS}

For SCTT measurements at least six animals were used in each group. The results are expressed as mean (SEM) and for statistical analysis the unpaired Student's $t$ test was used. A $5 \%$ probability level was chosen to indicate significance.

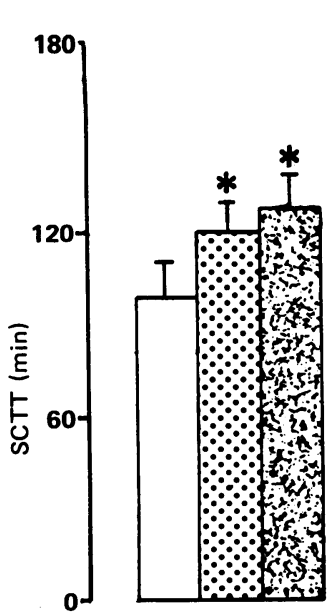

Figure 2: Effect of a single injection of $50 \mu \mathrm{g}$ (light hatched bar) or $75 \mu \mathrm{g}$ (dark hatched bar) of pancreatic glucagon on stomach to caecum transit time (SCTT) in the rat in comparison with a diluent injection (open bar) $\left({ }^{\star} p<0.05\right)$.

\section{Results}

EFFECT OF DIABETES ON SCT T

SCTT was unaffected by age in non-diabetic animals (Fig 1). The value obtained one week after injection with citrate buffer (average body weight $252 \mathrm{~g}$ ) was similar to that seven weeks later (average body weight $431 \mathrm{~g})(95$ (8) $\mathrm{min}$ and 104 (10) $\mathrm{min}$ respectively). The changes in SCTT during the progression of streptozotocinweek after injection, diabetes caused a significant delay in SCTT in injected rats when compared to aged matched controls (139 (11) min $v 95$ (8) $\min , \mathrm{p}<0.01)$. SCTT was also prolonged at two weeks (163 (16) min $v 101$ (10) min in controls, $\mathrm{p}<0.01$ ), four weeks (148 (9) $\mathrm{min} v 102$ (11) $\mathrm{min}$, $\mathrm{p}<0.01$ ), and eight weeks (171 (13) min $v 104$ (10) $\min , \mathrm{p}<0.01$ ).

EFFECT OF GLUCAGON ON SCTT

Figure 2 shows the effect of acute hyperglucagonaemia on SCTT. After $50 \mu$ g glucagon induced diabetes are shown in Figure 1. At one
SCTT was significantly slower than in control animals (96 (6) $\min v 120(7) \mathrm{min}, \mathrm{p}<0.05)$. The higher dose of glucagon $(75 \mu \mathrm{g})$ produced a further small delay in SCTT (127 (8) min, $\mathrm{p}<0.05$ compared to controls; not significantly different compared to $50 \mu \mathrm{g}$ ).

TRANSMURAL POTENTIAL DIFFERENCE

In three non-diabetic rats shown to have the ability to produce hydrogen, mannitol at a concentration of $50 \mathrm{mM}$ reduced transmural pd by $2.37(0.09) \mathrm{mV}$. This value was very similar to that obtained using $50 \mathrm{mM}$ lactulose $(2 \cdot 23(0.09)$ $\mathrm{mV} ; \mathrm{n}=3)$. In contrast, $50 \mathrm{mM}$ galactose and 50 $\mathrm{mM}$ sucrose produced the expected increases in pd $(3.42(0.68) \mathrm{mV}(\mathrm{n}=3)$ and $2.57(0.10) \mathrm{mV}$ $(n=3)$ respectively). In three non-hydrogen producers the changes in pd obtained using mannitol, lactulose, galactose, and sucrose (all at $50 \mathrm{mM})$ were $-2.43(0.12),-2.37(0.08),+3.86$ $(0 \cdot 52)$, and $+2 \cdot 7(0 \cdot 15) \mathrm{mV}$ respectively.

\section{Discussion}

Disturbances of gastrontestinal motility in diabetes mellitus are well recognised and are usually ascribed to manifestations of autonomic neuropathy. ${ }^{16}$ This conclusion is derived in part from studies where intestinal changes following truncal vagotomy and sympathectomy are similar to those seen in poorly controlled, longterm diabetes. ${ }^{17} 18$ There is also much support for diabetes induced histological alterations to autonomic nerves supplying the gastrointestinal tract and biochemical evidence of cholinergic and adrenergic denervation. ${ }^{10-12}$ These observations may explain the reduced sensitivity to intestinal distention and the symptoms of gastrointestinal motor dysfunction frequently noted in diabetic patients. ${ }^{119}$ Studies of intestinal motility in patients with diabetes, however, have been inconclusive $^{367}$ and, furthermore, give no information on changes occurring during the development of the disease.

In the present work we studied progressive changes in SCTT using an animal model of diabetes mellitus. The suitability of the streptozotocin injected rat for these experiments is shown by the early appearance of biochemical changes - for example, glycosuria - and the later occurrence of autonomic neuropathy as shown by neurochemical and histochemical changes. 112 The method used to estimate SCTT in this work is simple, non-invasive, and based on the measurement of hydrogen derived from bacterial metabolism of unabsorbed carbohydrate in the lumen of the lower intestinal tract. This method has been used by others to provide an index of gastrointestinal motility in the rat. ${ }^{14}$ Interestingly, in the present study no increase in hydrogen excretion was detected in $10 \%$ of rats. There are two possible reasons for this - namely, differences in the type or number of bacteria in the lower intestine ${ }^{20}$ or the removal of carbohydrate in the test meal by its digestion and absorption in the upper intestine. The electrophysiological results imply the absence of lactulase activity in the mucosa of the upper intestine since breakdown of lactulose would 
have resulted in an increase in the transmural pd owing to $\mathrm{Na}$ linked transport of galactose at the site of hydrolysis. Sucrose produced the expected rise in pd due to the electrogenic transport of glucose. Our data do not exclude the possibility that lactulose may be hydrolysed by the mucosa of the mid- or lower small intestine.

Results from our experiments showed a delayed SCTT in diabetic rats which was detected as early as one week after streptozotocin administration when autonomic neuropathy is unlikely to be involved in the response. ${ }^{12}$ Scott and Ellis ${ }^{21}$ have reported a reduced intestinal transit together with slower propagation of myoelectric activity in rats at a similar stage of diabetes.

Marked changes in hormonal and biochemical states occur in the first week of experimental diabetes and these may be relevant to the initial delayed SCTT. In particular, hyperglucagonaemia is a feature ${ }^{9}$ and raised plasma levels of pancreatic glucagon reduce gastrointestinal motility in humans. ${ }^{22}$ Using doses of the hormone which reflect those seen in experimental diabetes, ${ }^{923}$ we have shown an appreciable delay in SCTT. It is therefore tempting to suggest an association between increased endogenous levels of the hormone and the slower transit observed in diabetic rats.

It is also possible that other changes resulting from experimental diabetes, such as hyperglycaemia and hypoinsulinaemia, might mediate the changes in motility noted in this study. The precise factor responsible can only be identified from experiments designed to allow alteration of the plasma level of one of the three variables while controlling levels of the other two. Such experiments are, however, not technically feasible at the present time.

There is evidence that glucagon may have a wider role in the intestinal response to diabetes. Pronounced changes in intestinal nutrient absorption have been reported in rats treated with pancreatic glucagon, ${ }^{24}$ and it has been suggested that this hormone may affect the increased nutrient transport in diabetes. ${ }^{25}$ Glucagon, by its effect on motility, may also play a part in the hypertrophy which is a characteristic feature of the diabetic small intestine. ${ }^{26}$

We have shown a marked delay in SCTT in the diabetic rat. Hyperglucagonaemia is a likely factor in the early response, and autonomic neuropathy ${ }^{9-12}$ as well as an increased intestinal length ${ }^{27}$ may be relevant to the prolonged transit at later stages of diabetes. This study provides a basis for further investigations of the mechanisms in the development of diabetic gastroenteropathy.
Financial support from the Medical Research Council and the technical assistance of $\mathrm{Mr} \mathrm{H}$ Ebrahim are acknowledged.

1 Feldman M, Schiller LR. Disorders of gastrointestina motility associated with diabetes mellitus. Ann Intern Med 1983; 98: 378-84.

2 Campbell IW, Heading RC, Tothill P, Buist AS, Ewing DJ Clarke BF. Gastric emptying in diabetic autonomic neuropathy. Gut 1977; 18: 462-7.

3 Whalen GE, Soergel KH, Geenen JE. Diabetic diarrhea: a clinical and pathophysiological study. Gastroenterology 1969 ; 56: 1021-32.

4 Scarpello JHB, Sladen GE. Diabetes and the gut. Gut 1978 19: $1153-62$.

5 Katz LA, Spiro HM. Gastrointestinal manifestations of diabetes. NEngl f Med 1966; 275: 1350-61

6 Scarpello JHB, Graves M, Sladen GE. Small intestinal transi ime in diabetes. $\mathrm{Br}$ Med F 1976; ii: 1225-6.

7 NcNally EF, Reinhard AE, Schwartz PE. Small bowe motility in diabetics. Am F Dig Dis 1969; 14: 163-9.

8 Yoshida MM, Schuffler MD, Sumi SM. There are no morphological abnormalities of the gastric wall or abdominal vagus in patients with diabetes gastroparesis. Gastroenterology 1988; 94: 907-14.

9 Rudo ND, Lawrence AM, Rosenberg IH. Treatment with glucagon binding antibodies alters the intestinal response to glucagon binding antibodies alters the intestinal respon

10 Schmidt RE, Nelson JS, Johnson EM. Experimental diabetic autonomic neuropathy. Am $\mathcal{F}$ Pathol 1981; 103: 210-23.

11 Lincoln J, Bokor TT, Crowe R, Griffith SG, Haven AJ Burnstock G. Myenteric plexus in streptozocin treated rats. Neurochemical and histochemical evidence for diabetic neuropathy in the gut. Gastroenterology 1984; 86: 654-61.

12 Nowak TA, Harrington B, Kalbfleish JH, Amatruda JM. Evidence for abnormal cholinergic neuromuscular transmission in diabetic rat small intestine. Gastroenterology 1986; 91 : 124-32.

13 Patel DG. Effect of prolonged insulin treatment on blunted plasma catecholamine and glucagon increase during insulin hypoglycemia in streptozotocin diabetic rats. Metabolism 1983; 32: 377-82.

14 Brown NJ. An animal model for investigating the effect of infused nutrients into the ileum on stomach to caecum transit time (SCTT) using the rat. $\mathcal{F}$ Physiol 1986; 378: $14 \mathrm{P}$

15 Debnam ES, Levin RJ. An experimental method of identifying and qualifying the active transfer electrogenic component from the diffusive component during sugar absorption measured in vivo. $\mathcal{F}$ Physiol 1975; 246: 181-96.

16 Thomas PK, Eliasson SG. Diabetic neuropathy. In: Dyck PJ Thomas PK, Lambert EH, eds. Peripheral neuropathy. Philadelphia: WB Saunders, 1975: 956-81.

17 Kristensson K, Nordborg C, Olsson Y, Sourander P. Changes in the vagus nerve in diabetes mellitus. Acta Pathol Microbiol in the vagus nerve in diabe

18 Hensley GT, Soergel KH. Neuropathological findings in diabetes. Arch Pathol 1968; 85: 587-97.

19 Drewes VM. Mechanical and electrical activity in duodenum in diabetics with and without diarrhea: pressures, differen tial pressures and action potential. Am $\mathcal{f}$ Dig Dis $1971 ; 16$. 628-34.

20 Gilat T, Ben Hur H, Gelman-Malachi E, Terdiman R, Peled $Y$. Alterations of the colonic flora and their effect on the hydrogen breath test. Gut 1978; 19: 602-5.

21 Scott LD, Ellis TM. Small intestine transit and myoelectric activity in diabetic rat. In: Christensen J, ed. Gastrointestinal motility. New York: Raven Press, 1980: 395-9.

22 Dotevall G, Kock NG. The effect of glucagon on intestinal motility in man. Gastroenterology 1963; 45:364-7.

23 Rudo ND, Rosenberg IH, Wissler RW. The effects of partial starvation and glucagon treatment on intestinal villous morphology and cell migration. Proc Soc Exp Biol Med 1976 152: 277-80

24 Thompson CS, Debnam ES. Hyperglucagonaemia: effect on active nutrient uptake by the rat jejunum. $\mathcal{F}$ Endocrinol 1986 ; 111: $37-42$.

25 Debnam ES, Karasov WH, Thompson CS. Nutrient uptake by rat enterocytes during diabetes mellitus: evidence for an increased sodium electrochemical gradient. $\mathcal{f}$ Physiol 1988 ; 397: 503-12.

26 Johnson LR. Regulation of gastrointestinal growth. In Johnson LR, ed. Physiology of the gastrointestinal tract. New Johnson LR, ed. Physiology of the

27 Schedl HP, Wilson HD, Ramaswany K, Lichtenberg L. Gastrin and growth of the alimentary tract in the streptozotocin-diabetic rat. Am $\mathcal{F}$ Physiol 1982; 242 G460-3. 